\title{
Absorption and endogenous faecal excretion of calcium by low birthweight infants on feeds with varying contents of calcium and phosphate
}

\author{
D. BARLTROP, R. H. MOLE, AND ALICE SUTTON
}

From St. Mary's Hospital Medical School, London, and the MRC Radiobiology Unit, Harwell

SUMMARY Low birthweight infants aged 4-41 days were given from birth one of three experimental milk formulae varying widely in content of calcium and phosphate. $\mathrm{Ca}$ and $\mathrm{P}$ in feed, urine, and faeces were measured between carmine markers corresponding to a metabolic period of 48 hours. Calcium enriched in ${ }^{46} \mathrm{Ca}$ to provide a marker for the dietary $\mathrm{Ca}$ was added to one feed and ${ }^{46} \mathrm{Ca}$ measured in urine and faeces. True absorption of $\mathrm{Ca}$ and endogenous excretion into the bowel could then be inferred. True absorption of $\mathrm{Ca}$ was proportional to $\mathrm{Ca}$ intake and independent of $\mathrm{P}$ intake. Endogenous faecal excretion seemed to be independent of both $\mathrm{Ca}$ and $\mathrm{P}$ intakes, and varied widely between different infants in the range 4-150 mg/day. Urine Ca was low and retention was essentially the difference between true absorption and endogenous faecal excretion. Retention of $\mathrm{Ca}$ tended to be much greater on a high $\mathrm{Ca}$ intake, but the variability in retention between infants on a given intake was large, paralleling the variability in endogenous faecal excretion.

The variability in plasma $\mathrm{Ca}$ concentrations in newborn infants may in part be a consequence of wide individual variability in endogenous faecal excretion. The ${ }^{46} \mathrm{Ca}$ marker technique provides a means of investigating the factors determining this variability.

The tendency towards hypocalcaemia is greater in newborn infants fed cows' milk than in corresponding breast-fed infants (Barltrop and Oppé, 1970), especially when the cows' milk formula contains concentrations of phosphorus greatly in excess of that in breast milk (Oppé and Redstone, 1968). Neonatal hypocalcaemia can be prevented by the addition of calcium to the cows' milk formula, suggesting that the mass of $\mathrm{Ca}$ reaching the plasma from cows' milk formulae is less adequate than from breast milk (Barltrop and Oppé, 1970). Nevertheless the intake of $\mathrm{Ca}$ from cows' milk formulae usually exceeds that from breast milk (Shaw et al., 1973), implying that the absorption of $\mathrm{Ca}$ from cows' milk is impaired. It is generally agreed that the mechanisms involved are complex and not fully understood: both the amounts of $P$ and fat consumed and the composition of the dietary fat have been implicated.

In newborn breast-fed infants a phosphate supplement given during a 3-day study did not reduce the retention of $\mathrm{Ca}$ (Widdowson et al., 1963). More Received 6 May 1976 recently Barltrop and Oppé (1970) observed a correlation between the concentration of $\mathrm{Ca}$ in the plasma of infants and the $\mathrm{Ca} / \mathrm{P}$ ratio of different feeds, breast milk, and 5 milk formulae.

The triglyceride content of cows' milk formulae differs from breast milk and unabsorbed fatty acids may interfere with the absorption of calcium (Southgate et al., 1969). Olive oil is well absorbed, butterfat less so, but the retention of $\mathrm{Ca}$ by preterm infants was similar in the presence of either fat in otherwise identical formulae (Barltrop and Oppé, 1973a).

The purpose of this investigation was to discover whether large changes in the dietary $\mathrm{Ca} / \mathrm{P}$ ratio induce changes in the absorption, retention, and endogenous faecal excretion of $\mathrm{Ca}$ in newborn infants of low birthweight. The results are given from 16 studies involving 13 infants and three experimental milk formulae differing only in the content of $\mathrm{Ca}$ and $\mathrm{P}$. The measurement of true absorption requires a method which distinguishes between faecal $\mathrm{Ca}$ of dietary origin and that which is derived from endogenous excretion. This has 
been achieved by means of ${ }^{46} \mathrm{Ca}$, a nonradioactive tracer isotope added to a single feed during a conventional metabolic balance. True absorption and endogenous faecal excretion of the natural $\mathrm{Ca}$ in the diet have been inferred by applying the equations of Aubert et al. (1963) to measurements of the ${ }^{46} \mathrm{Ca}$ and natural $\mathrm{Ca}$ in the urine, faeces, and diet. Data from 4 infants have already been reported (Sutton and Barltrop, 1973) and are included together with new data from 9 further infants.

\section{Materials and methods}

Twelve male infants and 1 female of low birthweight were studied in the special care baby unit of St. Mary's Hospital. They were aged 4 to 41 days at the start of the investigation. Infants were selected because they were not breast fed and had no gastrointestinal disturbance or other symptom. Parental consent to the investigation was given. Each infant was fed on the experimental formula from birth to completion of the metabolic balance.

Three milk formulae based on formula $1610 \mathrm{~F}$ (Barltrop and Oppé, 1970) were used; L, Ca/P 0.56 (phosphate supplemented); $\mathrm{M}, \mathrm{Ca} / \mathrm{P} 1.4$; and $\mathrm{H}$, $\mathrm{Ca} / \mathrm{P} 2.4$ (calcium supplemented). They differed in the amount of $\mathrm{Ca}$ and $\mathrm{P}$ per feed and therefore in the ratio of $\mathrm{Ca}$ to $\mathrm{P}$, but were otherwise identical. They were prepared by Glaxo Laboratories from a carbohydrate modified cows' milk formula adjusted to constant fat/protein ratio and incorporating appropriate supplements of vitamins and iron.

The $\mathrm{Ca}$ marker, as a neutral solution containing $2.0 \mathrm{mg}$ of $\mathrm{Ca}$ as the chloride enriched in the stable nuclide ${ }^{46} \mathrm{Ca}$, was mixed with a single normal feed and administered 3 to 4 hours after the infant's previous feed. The intake of milk from the marked feed was measured and, when a metabolic balance of natural $\mathrm{Ca}$ was to be determined, from subsequent feeds also. Stools, urine, and vomitus were collected for a 'nominal' 48-hour period (see Sutton et al., 1977). Carmine was added to the marked feed and again to the feed given 48 hours later. The 48-hour faecal collection began with the first carmine-coloured stool and ended with the last stool before the coloured stool, irrespective of the exact timing of the specimens.

The whole of each specimen of stool, vomitus, and milk and the greater part of the urine specimens were dried and thermally ashed. The Ca content of aliquots of the unashed urine and of the acid extracts of the ash from the other specimens was determined by atomic absorption spectrophotometry to obtain the value $W, \mathrm{mg} \mathrm{Ca}$ in the original specimen. Acid extracts of ash from each of the specimens were treated with oxalate and the alkaline earths precipitated. The oxalate samples together with standards of natural and of ${ }^{46} \mathrm{Ca}$ enriched $\mathrm{Ca}$ were exposed to neutron irradiation in a nuclear reactor. Measurements of ${ }^{46} \mathrm{Ca}$ were made from radioactive ${ }^{47} \mathrm{Ca}$ produced during neutron irradiation. The $\gamma$-ray activity due to ${ }^{47} \mathrm{Ca}$ was determined using an Intertechnique 400 channel analyser with a well type NaI crystal as detector. Details of the procedure for the collection and assay of specimens have been reported previously (Barltrop and Sutton, 1972).

After irradiation radioactive contaminants were removed chemically and loss of $\mathrm{Ca}$ and ${ }^{47} \mathrm{Ca}$ during these procedures was reduced by first adding known amounts of $\mathrm{Ca}$ carrier. Loss of $\mathrm{Ca}$ was also possible during the precipitation of oxalate before irradiation. Therefore two additional measurements of Ca were made using atomic absorption spectrophotometry on the irradiated dissolved oxalate before the addition of carrier, value $Y$, and on the final solution after counting, value $Z$.

The marker content of specimens was determined using the expression

$$
\mathbf{M S}_{\mathbf{m}}+\mathrm{WS}_{\mathbf{n}}=\mathrm{C}\left[\frac{\mathrm{W}}{\mathrm{Y}} \frac{\mathrm{Y}+\text { Carrier }}{\mathrm{Z}}\right]
$$

where $M=\mu \mathrm{g}$ marker in $\mathrm{Ca}$ in the original specimen, $S_{m}=$ specific activity ${ }^{47} \mathrm{Ca} / \mu \mathrm{g} \mathrm{Ca}$ in the marker $\mathrm{Ca}$ standard, $W=\mathrm{mg} \mathrm{Ca}$ in original specimen, $S_{n}=$ specific activity ${ }^{47} \mathrm{Ca} / \mathrm{mg} \mathrm{Ca}$ in natural $\mathrm{Ca}$ standard, $\mathrm{C}={ }^{47} \mathrm{Ca}$ in sample counted. The term in brackets is the correcting factor for $\mathrm{Ca}$ losses during the preparation of the sample to be counted. Duplicate aliquots of specimens were irradiated and assayed whenever sufficient amounts of material were available: usually only faeces met this criterion. The coefficient of variation of the means of duplicate observations was $\pm 2 \cdot 2 \%$. Marker $\mathrm{Ca}$ was regarded as measurable when the count rate of ${ }^{47} \mathrm{Ca}$ was $5 \%$ in excess of that attributable to the natural ${ }^{46} \mathrm{Ca}$ in the sample counted.

Measurements of $\mathbf{P}$ were made on the unashed urine and on the acid extracts of the ashed specimens of faeces and milk using the method of Fogg and Wilkinson (1958).

Retention of natural $\mathbf{C a}$ or $\mathbf{P}$ was defined as Intake-(urine + faeces) and was derived directly from the measurements of natural $\mathrm{Ca}$ or P. Absorption and endogenous faecal excretion of natural $\mathrm{Ca}$ were derived from the following equations of Aubert et al. (1963) which assume that all the ingested $\mathrm{Ca}$ is equally available for absorption, and that the natural $\mathrm{Ca}$ in the diet is therefore freely exchangeable with the marker, 


$$
\begin{gathered}
v_{f}=\frac{\left.v_{u}\left(v_{F} R_{i n g}-v_{i} R_{F}\right]_{0}^{t}\right)}{\left.v_{u} R_{\text {ing }}-v_{i} R_{u}\right]_{0}^{t}} \\
\left.R_{f}\right]_{0}^{t}=\frac{\left.v_{f} R_{u}\right]_{0}^{t}}{v_{u}} \\
v_{a}=v_{i}-v_{F}+v_{f}
\end{gathered}
$$

where $v_{a}=C a$ absorbed from intestine, $v_{f}=$ faecal endogenous $\mathrm{Ca}, \mathrm{v}_{\mathrm{F}}=$ total faecal $\mathrm{Ca}, \mathrm{v}_{\mathbf{i}}=\mathrm{Ca}$ ingested in food, $v_{u}=$ urinary $\mathrm{Ca}, \mathbf{R}_{\text {ing }}=$ marker ingested at time $=0, R_{f}=$ marker due to endogenous faecal $\mathrm{Ca}$, $\mathbf{R}_{\mathbf{F}}=$ marker in faeces, $\mathbf{R}_{\mathbf{u}}=$ marker in urine, $]_{0}^{t}=$ sum from time $=o$ to time $=t$. These equations are based on Aubert's scheme 1 in which the unphysiological assumption is made that endogenous faecal $\mathrm{Ca}$ is secreted into the bowel and is not subject to intestinal absorption (see Discussion).

Aubert's equations allow true absorption and endogenous faecal excretion to be calculated from a metabolic study in which a single administration of marker is given, and complete collections of urine and faeces are made over some given time period, the exact length of which would be immaterial if it were not for the difference in timing between excretion by the kidney and urination on the one hand and excretion into the bowel and defecation on the other. In practice, therefore, the total urinary and faecal excretion of the marker must be determined. The importance of complete collection is shown elsewhere (Sutton et al., 1977). The equations of Aubert et al. (1963) were derived on the assumption of steady state conditions, an assumption which is unlikely to be exactly true of the infants of this study. They discussed in detail the theoretical and physiological limitations in studying $\mathrm{Ca}$ metabolism when only oral administration of marker is used and no additional observations are made after intravenous administration of marker.

Since Aubert's requirement for steady state conditions cannot be known to be met, the notation will not be used in presenting results. Instead more familiar symbols are used, $I, F, U$, for measured intake, faecal excretion, and urinary excretion per day of natural $\mathrm{Ca}$; and $R, A, E$ for the derived quantities, retention, true absorption, and endogenous faecal excretion of natural $\mathrm{Ca}$ per day. These are not independent, for $R=I-F-U=A-E-U$, by definition. $R$ is derived directly from observations by difference. $A$ and $E$ are derived using Aubert's equation and this is possible only if all six measurements are made for the study period, $I, F$, and $U$ for natural $\mathrm{Ca}$, and the corresponding measurements for the marker; sometimes these were not all available (Table 1). There is no interest in the values for the marker as such but only in the derived quantities $A$ and $E$ which the data about the marker allow to be calculated. One basic assumption of Aubert's equations is that the fractional absorption $A / I$ is assumed to be the same for both marker and natural Ca.

\section{Results}

The measured quantities $I, F$, and $U$ for natural $\mathrm{Ca}$ and the corresponding data for marker $\mathrm{Ca}$ are given in Tables 1 and 2 and for $\mathbf{P}$ in Table 3. $U$ for natural calcium and ${ }^{46} \mathrm{Ca}$ was $0 \cdot 4-1 \cdot 8 \%$ and $0 \cdot 07-2 \cdot 1 \%$ of $F$, respectively. Faecal contamination of urine samples was a potential source of error, but is believed not to have occurred. The coefficient of variation of urinary content among different infants on any one formula was in the range $20-30 \%$ for $\mathrm{Ca}$ and ${ }^{46} \mathrm{Ca}$ (Table 1), but was less, $4-13 \%$, for $P$ (Table 3). The corresponding coefficients of variation of $I$ and $F$ for the different infants were in the range $2-15 \%$ for all three feeding regimens. However, the ratio ${ }^{46} \mathrm{Ca} /$ natural $\mathrm{Ca}$ in urine was less variable between infants, so that the derived values for $A$ and $E$ were also less variable than might have been expected. The variation between infants on a given diet for ${ }^{46} \mathrm{Ca}$ in urine and faeces was usually much less than for natural calcium. As would be expected, there were marked correlations between the ${ }^{46} \mathrm{Ca}$ and natural $\mathrm{Ca}$ content of each specimen.

Before considering the data in detail the degree of variability in the mean values (SEs are given in the Tables) and of reproducibility of the observations should be noted. Repeat observations were made on 3 subjects, one on each kind of feed. Those on Case 6 on milk $M$ were as similar as could be expected, those on Case 1 on milk $L$ and Case 9 on milk $H$ showed substantial differences in $F$ and $R$ for natural $\mathrm{Ca}$, and, for Case 1 only, also in ${ }^{46} \mathrm{Ca}$ retention. It appears that this degree of variation was of the same order as the variation between different infants. The three greatest values of retention and three lowest values of faecal excretion of the marker were provided by four observations on two pairs of twins (Table 1, col. 10, 12). Balance data for natural $\mathrm{Ca}$ were obtained for only one pair (on milk $\mathrm{L}$ ) and gave substantially different values for $\boldsymbol{A}$ and $R$ and also for faecal content of marker and the consequential values of retention, absorption, and endogenous faecal excretion of marker (Table 1, col. 7, 8, 10, 12, 13). Measurement of $U, F$, and $R$ should be valid for 
Table 1 Intake of natural Ca and absorption, excretion, and retention of both natural and ${ }^{46} \mathrm{Ca}$ marker Ca in infants fed theee

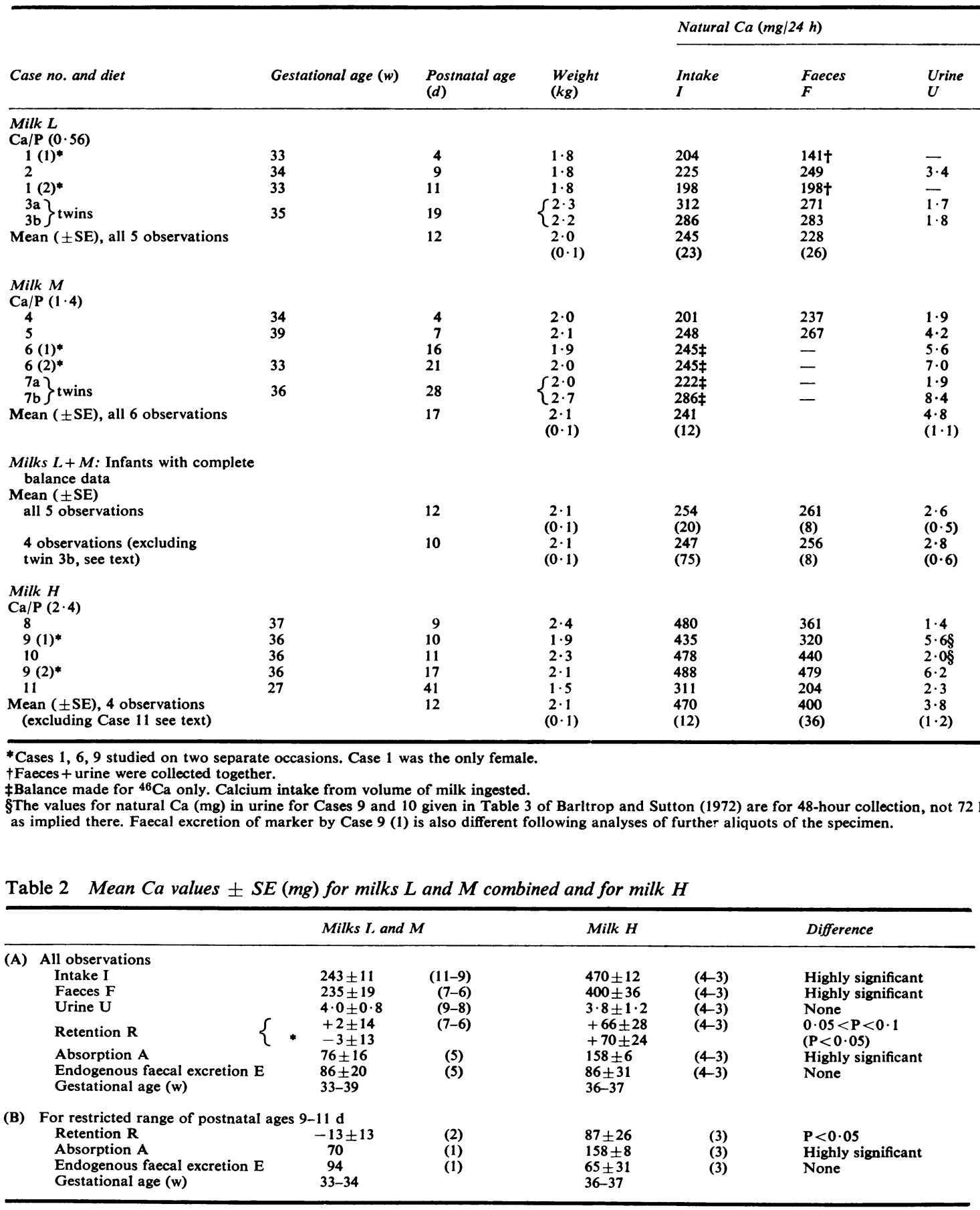


different milks

\begin{tabular}{|c|c|c|c|c|c|c|c|}
\hline \multirow[b]{2}{*}{$\begin{array}{l}\text { Retention } \\
R\end{array}$} & \multirow[b]{2}{*}{$\begin{array}{l}\text { Absorption } \\
\text { A }\end{array}$} & \multirow[b]{2}{*}{$\begin{array}{l}\text { Endogenous } \\
\text { faecal excretion } \\
\text { E }\end{array}$} & \multicolumn{5}{|c|}{${ }^{46} \mathrm{Ca}$ marker as $\%$ of intake } \\
\hline & & & Faeces & Urine & Retention & $\begin{array}{l}\text { Absorption } \\
A / I\end{array}$ & $\begin{array}{l}\text { Endogenous } \\
\text { faecal excretion }\end{array}$ \\
\hline $\begin{array}{r}+63 \\
-27 \\
0 \\
+39 \\
+1 \\
+15 \\
(16)\end{array}$ & $\begin{array}{r}\overline{70} \\
\overline{65} \\
153\end{array}$ & $\begin{array}{r}\overline{94} \\
\overline{24} \\
150\end{array}$ & $\begin{array}{l}65 t \\
74 \\
86 t \\
81 \\
56 \\
72 \\
(5 \cdot 4)\end{array}$ & $\begin{array}{l}\overline{0.20} \\
\overline{0.11} \\
0 \cdot 11\end{array}$ & $\begin{array}{l}35 \\
26 \\
14 \\
19 \\
44 \\
28 \\
(5 \cdot 4)\end{array}$ & $\begin{array}{l}\overline{31} \\
\overline{21} \\
53\end{array}$ & $\begin{array}{l}\overline{5 \cdot 5} \\
\overline{1 \cdot 4} \\
9 \cdot 3\end{array}$ \\
\hline $\begin{array}{l}-38 \\
-23 \\
- \\
- \\
- \\
-\end{array}$ & $\begin{array}{l}43 \\
65 \\
- \\
- \\
- \\
-\end{array}$ & $\begin{array}{l}79 \\
85 \\
- \\
- \\
- \\
-\end{array}$ & $\begin{array}{l}83 \\
77 \\
67 \\
64 \\
38 \\
31 \\
60 \\
(8 \cdot 7)\end{array}$ & $\begin{array}{l}0 \cdot 09 \\
0 \cdot 20 \\
0 \cdot 22 \\
0 \cdot 19 \\
0 \cdot 15 \\
0 \cdot 67 \\
0 \cdot 25 \\
(0 \cdot 09)\end{array}$ & $\begin{array}{l}17 \\
23 \\
33 \\
36 \\
62 \\
69 \\
40 \\
(8 \cdot 6)\end{array}$ & $\begin{array}{l}21 \\
26 \\
- \\
- \\
-\end{array}$ & $\begin{array}{l}3 \cdot 7 \\
3 \cdot 1 \\
- \\
- \\
-\end{array}$ \\
\hline $\begin{array}{l}-10 \\
(14) \\
-12 \\
(17)\end{array}$ & $\begin{array}{l}79 \\
(19) \\
61 \\
(6)\end{array}$ & $\begin{array}{l}86 \\
(20) \\
71 \\
(16)\end{array}$ & $\begin{array}{l}74 \\
(4 \cdot 8) \\
79 \\
(2 \cdot 0)\end{array}$ & $\begin{array}{l}0 \cdot 14 \\
(0 \cdot 02) \\
0 \cdot 15 \\
(0 \cdot 03)\end{array}$ & $\begin{array}{l}26 \\
(4 \cdot 8) \\
21 \\
(2 \cdot 0)\end{array}$ & $\begin{array}{l}31 \\
(6 \cdot 1) \\
25 \\
(2 \cdot 4)\end{array}$ & $\begin{array}{l}4 \cdot 6 \\
(1 \cdot 3) \\
3 \cdot 4 \\
(0 \cdot 8)\end{array}$ \\
\hline $\begin{array}{r}+117 \\
+109 \\
+36 \\
+3 \\
+105 \\
+66 \\
(28)\end{array}$ & $\begin{array}{l}142 \\
161 \\
171 \\
159 \\
111 \\
158 \\
(6)\end{array}$ & $\begin{array}{r}23 \\
46 \\
126 \\
150 \\
4 \\
86 \\
(31)\end{array}$ & $\begin{array}{l}71 \\
65 \S \\
72 \\
71 \\
67 \\
70 \\
(1 \cdot 6)\end{array}$ & $\begin{array}{l}0 \cdot 05 \\
0 \cdot 23 \\
0 \cdot 10 \\
0 \cdot 15 \\
0 \cdot 20 \\
0 \cdot 13 \\
(0 \cdot 04)\end{array}$ & $\begin{array}{l}30 \\
34 \\
28 \\
29 \\
33 \\
30 \\
(1 \cdot 3)\end{array}$ & $\begin{array}{l}30 \\
37 \\
34 \\
33 \\
34 \\
33 \\
(1 \cdot 4)\end{array}$ & $\begin{array}{l}1 \cdot 1 \\
1 \cdot 8 \\
6 \cdot 3 \\
3 \cdot 6 \\
0 \cdot 3 \\
3 \cdot 2 \\
(1 \cdot 2)\end{array}$ \\
\hline
\end{tabular}

Table 3 Intake $(I)$, excretion $(F+U)$, and retention of phosphorus in infants receiving milk formula $L, M$, or $H$

\begin{tabular}{|c|c|c|c|c|c|c|}
\hline \multirow[b]{2}{*}{ Milk and $\mathrm{Ca} / \mathrm{P}$ ratio } & \multirow[b]{2}{*}{ Case no. } & \multicolumn{4}{|c|}{ Phosphorus (mg/d) } & \multirow{2}{*}{$\begin{array}{l}\text { Calcium }(m g / d) \\
\text { retention }\end{array}$} \\
\hline & & Intake & Faeces & Urine & $\begin{array}{l}\text { Retention } \\
I-(F+U)\end{array}$ & \\
\hline $\mathbf{L}$ & 2 & 401 & 71 & 293 & 37 & \\
\hline \multirow{2}{*}{0.56} & $3 a$ & 560 & 106 & 282 & 172 & \\
\hline & $3 b$ & 510 & 89 & 257 & 164 & \\
\hline \multirow{3}{*}{$\begin{array}{l}\text { Mean } \\
\pm \text { SE } \\
\mathbf{M}\end{array}$} & & 490 & 89 & 277 & 124 & 4 \\
\hline & & \pm 47 & \pm 10 & \pm 11 & \pm 44 & \pm 19 \\
\hline & 4 & 144 & 73 & 103 & -32 & \\
\hline \multirow[t]{4}{*}{$1 \cdot 4$} & $\begin{array}{l}5 \\
6(1)^{*}\end{array}$ & $\begin{array}{l}177 \\
175+\end{array}$ & 55 & $\begin{array}{l}90 \\
64\end{array}$ & 32 & \\
\hline & $6(2)^{*}$ & $175 \dagger$ & & 88 & & \\
\hline & $7 a$ & $159 \dagger$ & & 60 & & \\
\hline & & $204 \dagger$ & & 84 & & \\
\hline \multirow{3}{*}{$\begin{array}{l}\text { Mean } 6 \text { subjects } \\
\pm \mathrm{SE} \\
2 \text { subjects }\end{array}$} & & 172 & & 82 & & \\
\hline & & $\begin{array}{l} \pm 8 \\
161\end{array}$ & 64 & \pm 7 & 0 & -31 \\
\hline & & $\begin{array}{r}17 \\
+17\end{array}$ & $\begin{array}{l}9 \\
\pm 9\end{array}$ & & \pm 32 & $\begin{array}{r}-31 \\
\pm 8\end{array}$ \\
\hline \multirow[t]{2}{*}{$\mathbf{H}$} & 8 & 200 & 71 & 45 & 84 & \\
\hline & $9(1)^{*}$ & 180 & 65 & 43 & 72 & \\
\hline \multirow[t]{3}{*}{$2 \cdot 4$} & 10 & 199 & 81 & 31 & 87 & \\
\hline & $9(2)^{*}$ & 203 & 92 & 53 & 58 & \\
\hline & 11 & 130 & 29 & 25 & 77 & \\
\hline \multirow{2}{*}{\multicolumn{2}{|c|}{$\begin{array}{l}\text { Mean } \\
\pm \mathrm{SE}\end{array}$}} & 182 & 68 & 39 & 76 & 74 \\
\hline & & \pm 14 & \pm 11 & \pm 5 & \pm 4 & \pm 23 \\
\hline
\end{tabular}

*Cases 6 and 9 each studied on 2 separate occasions. 
Case $3 \mathrm{~b}$ but the deduced values $A$ and $E$ may be in error because of the possibility that faecal excretion of the marker was still incomplete at the termination of the collection period (Sutton et al., 1977).

Mean values for calcium. Five sets of complete balance data are available with milk $\mathrm{H}$ but only 3 with milk $L$ and 2 with milk $M$. As well as milk composition, there were inevitably a variety of factors which might be thought $a$ priori as possibly influencing $\mathrm{Ca}$ metabolism such as gestational age, postnatal age, and body mass. Case 11 on milk $\mathrm{H}$ was the single extreme case with the smallest gestational age, greatest postnatal age, and smallest body mass (Table 1). Milks $L$ and $M$ contained the same quantity of $\mathrm{Ca}$ per feed differing only in $\mathrm{P}$ content. $I, F, R, A$, and $E$ for $\mathrm{Ca}$ were indistinguishable (Table 1, col. 4-9). The combined observations may therefore be compared with those for milk $\mathbf{H}$ excluding Case 11 (Table 2A). The mean values for $I, F$, and $A$ for milk $\mathrm{H}$ were clearly significantly larger than for milks $L$ and $M$. In contrast $F / I$ was smaller on milk $\mathrm{H}$. Values for urinary and endogenous faecal excretion might be expected to depend on physiological factors, not so much on diet, and mean values for $U$ and $E$ were in fact identical. Retention $R$ was greater on milk $\mathrm{H}$ but the difference from milks $L$ and $M$ was only at the borderline of conventional statistical significance. The mean values of $R$ were close to those found in earlier observations on low birthweight infants in the same hospital, namely, $R=+75 \mathrm{mg}$ for $I=400 \mathrm{mg}$ and $R$ $=-14 \mathrm{mg}$ for $I=200 \mathrm{mg}$ (Barltrop and Oppé, 1973b). The correlation between a greater $R$ for $\mathrm{Ca}$ and a lesser urinary excretion of $\mathbf{P}$ is considered below.

The range of gestational age for the observations on which mean $R, A$, and $E$ depend was 33-39 weeks for milks $L$ and $M$ and 36-37 weeks for milk $H$, and the corresponding range of postnatal age was 4-19 days and 9-17 days respectively (Table 1). In the narrower postnatal age range 9-11 days there were two observations, one incomplete, on milk $L$ and three on milk $\mathbf{H}$. In spite of the small number of subjects there were clear differences in $R$ and $A$ but not $E$ (Table 2B). These differences will be the consequence of the differences in dietary composition unless it is claimed that they are attributable to the 2- to 3-week difference in gestational age (Table 2B).

Correlations in individual infants. As shown in Fig. 1 there was a linear regression of the derived quantity $A$ on measured $I$ for the 10 observations ( 9 subjects including one pair of twins and Case 11).

$$
A=-12( \pm 30)+0 \cdot 36( \pm 0 \cdot 08) I \text {. }
$$

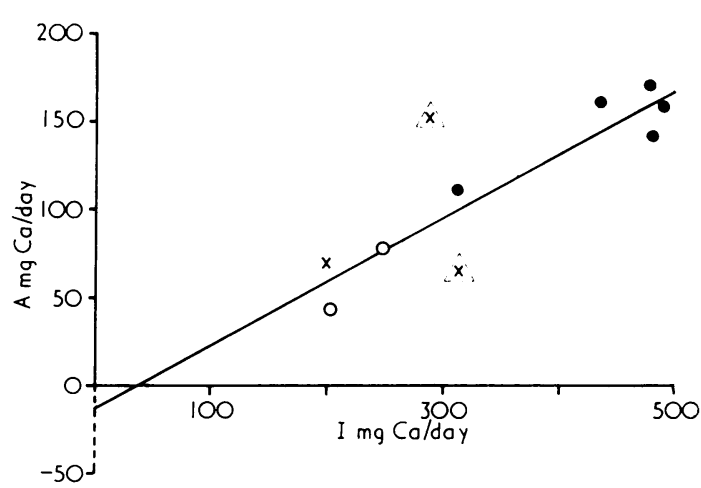

Fig. I Truc absorption A and dietary intake I of Ca for low birthweight infants on different levels of $C a$ intake. Milk $H \bigcirc$, milk $M \cap$, milk $L$ singleton $\rtimes$, twins Cases $3 a$ and $h_{\llcorner} \hat{x}_{\perp}$. The calculated least-squares best-fitting regression line for $\mathrm{A}$ on $\mathrm{I}$ is $\mathrm{A}=-12( \pm 30)+$ $0 \cdot 36(0 \cdot 08) \mathrm{I}$.

Thus percentage $\mathrm{Ca}$ absorption was found to have a constant value $36 \pm 8 \%$ independent of level of $\mathrm{Ca}$ intake over the range of the observations. The regression line did not deviate significantly from the origin suggesting that in these cases much the greater part, if not all, of the dietary Ca was available for absorption. The assumption that the marker equilibrated with the dietary $\mathrm{Ca}$ seems justifiable, thus overcoming the main physiological limitation of the oral method for examining calcium absorption as discussed by Aubert et al. (1963).

By definition $R=A-(E+U)$ for an individual, and the above equation (Fig. 1 ) shows that $R=0 \cdot 36$ $I-(E+U)-12$. Thus $R$ is clearly dependent on dietary intake $I$. On a given level of intake, however, $R$ was very variable (Table 1 ) so that $R$ for an individual depended as much on $E$ as on $I$. Nevertheless, mean $E$ varied little between the three different milks, lying in the range 70-89 $\mathrm{mg}$ (Tables 1, 2), and was largely, if not wholly, independent of $I$, unlike $R$ (cf. Table 2). If $E$ is physiologically determined, it might not be dependent on diet and the observed variation in $E$ suggests that its value is a characteristic of an individual infant. Within the milk $\mathbf{H}$ group individual observations deviated little from the expected linear correlation $R=c+b E$ with $b=-1$ suggesting that random variation was small (Fig. 2). The most aberrant point is for Case 11, the infant of smallest gestational age and body mass as already noted, who had a value of only $4 \mathrm{mg}$ for $E$ : if he is included $b=-0 \cdot 76+0 \cdot 13$, if he is excluded $b=$ $-0.90 \pm 0.08$ (Fig. 2). In either case $R$ would be $130-150 \mathrm{mg} /$ day when $E=$ nil, and nil when $E=$ $160-170 \mathrm{mg} /$ day.

The points for 4 of the 5 infants on milks $L$ and $M$ 


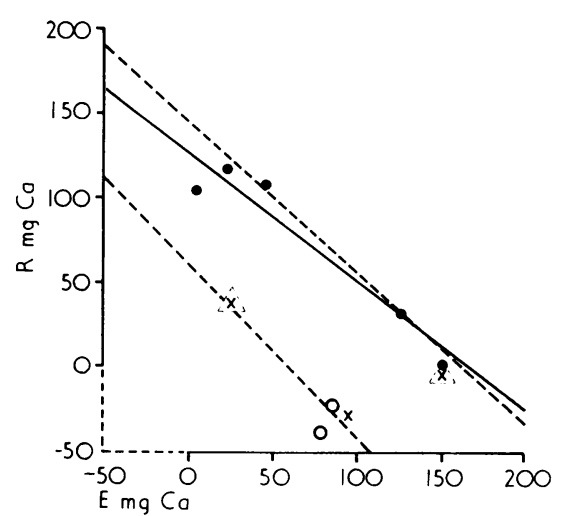

Fig. 2 Retention $\mathrm{R}$ and endogenous faecal excretion $\mathrm{E}$ of Ca for low birthweight infants on different levels of $\mathrm{Ca}$ intake. Milk $H \bigcirc$, milk $M$ C, milk L singleton $\times$, twins Cases $3 a$ and $b \hat{\underline{x}}$. The calculated least-squares best-fitting regression lines for $\mathrm{R}$ on $\mathrm{E}$ are (i) milk $\mathrm{H}$, all 5 observations: $\mathrm{R} \quad 127( \pm 12)-0 \cdot 76( \pm 0 \cdot 13) \mathrm{E}$; (ii) milk $H$, excluding Case II (see text): $\mathrm{R}=144( \pm 8)$ $0.90( \pm 0.08) \mathrm{E} ;($ iii) milks $L$ and $M, 4$ subjects (excluding twin, Case $3 b): \mathrm{R}-61( \pm 20)-1 \cdot 04( \pm 0 \cdot 26)$ E.

are widely separated from the points for milk $\mathrm{H}$ (Fig. 2) and could be regarded as fitting another linear regression of similar slope $b=-1 \cdot 04 \pm 0 \cdot 26$. The value for $c$ would be different and determined by the level of dietary $\mathrm{Ca}$ : its calculated value is $70-80$ $\mathrm{mg}$ smaller than for milk $\mathbf{H}$ (Fig. 2), corresponding to the difference in $\mathrm{Ca}$ absorption $\mathrm{A}_{1}-\mathrm{A}_{2}=0 \cdot 36\left(\mathrm{I}_{1}-\mathrm{I}_{2}\right)$ $=0.36(470-247)=80 \mathrm{mg}$ and the difference in mean $E$ of $86-71=+15 \mathrm{mg}$. The common slope to the 8 observations (excluding Case 11) $=-0.93 \pm$ 0.09 . These additional data from milks $L$ and $M$ could thus be regarded as confirming the inference made in the previous paragraph about physiological differences between different infants in $E$ and its independence of dietary $\mathrm{Ca}$ levels. All the calculated values of $b$ are close to and not statistically different from -1 .

However, the point for the fifth subject in this combined group for milks $L$ and $M$, Case $3 b$ is quite aberrant (Fig. 2). He had an unusually high value for $A / I$ and perhaps for endogenous faecal excretion of the marker (Table 1). Considerations discussed elsewhere (Sutton et al., 1977) suggest that this might be the result of incomplete recovery of faecal marker. If both the twins (Cases 3a, b) are omitted, no data are available to provide a value for the slope of $R$ on $E$ for milks $\mathrm{L}$ and M. The mean value of $R$ for the remaining 3 observations is about $90 \mathrm{mg}$ less than would be expected from the regression line for milk $\mathrm{H}$ for infants with the same $\mathrm{E}$, reasonably close to the value $A_{1}-A_{2}=0 \cdot 36\left(I_{1}-I_{2}\right)=0 \cdot 36(470-225)=88 \mathrm{mg}$.
It is concluded that the existence of the aberrant point for Case $3 b$ does not necessarily disprove the inferences drawn from the infants on milk $\mathrm{H}$. Overall it is perhaps suprising that the data were so selfconsistent considering the likely deviations from the basic assumption of steady state conditions and the problems involved in metabolic studies of very young infants.

Phosphorus. Average phosphorus intakes on milks $L$ and $M$ were 490 and $172 \mathrm{mg}$ daily respectively (Table 3). The three nontwin infants on milks $\mathrm{L}$ and $\mathbf{M}$ for whom complete metabolic data are available had daily intakes of 401,144 , and $177 \mathrm{mg} \mathrm{P}$ (Table 3) and there was no obvious difference between them in $R, A$, or $E$ for $\mathrm{Ca}$, suggesting that the differences in $\mathbf{P}$ intake were not directly relevant to $\mathrm{Ca}$ metabolism. The inclusion of the twins (Cases 3a, b) on the high-phosphorus milk $L$ altered only slightly the mean values of $R, A$, or $E$, for $\mathrm{Ca}$ (Table 1), supporting this conclusion.

The urinary excretion of $\mathbf{P}$ seemed to depend on intake of $\mathrm{Ca}$ but not $\mathrm{P}$. The proportion of dietary $\mathrm{P}$ in the urine was greatest, $58 \pm 8 \%$, for milk $\mathrm{L}$, where intake of $P$ was $490 \mathrm{mg} /$ day. Reducing $P$ intake to $172 \mathrm{mg}$ without altering $\mathrm{Ca}$ intake (milk $\mathrm{M}$ ) reduced the proportion excreted in the urine nonsignificantly to $48 \pm 5 \%$. This comparison together with the lack of change in faecal $\mathbf{P}$ (Table 2) suggests that most of the ingested $\mathbf{P}$ was absorbed. Doubling $\mathrm{Ca}$ intake while keeping $P$ intake constant $(182 \mathrm{mg}$ milk $\mathrm{H}$ versus $172 \mathrm{mg}$ milk $M$ ) did not increase faecal $P$ excretion, suggesting that most of it was still available for absorption, but halved urinary excretion to $21 \pm 2 \%$. An increased formation of bone salt on the high-calcium milk $\mathbf{H}$ could be at least a partial explanation of the concomitant halving of the urinary $\mathbf{P}$ on milk $\mathbf{H}$ as compared with milk $\mathbf{M}$ (Table 3). If so, a linear correlation between retention of $\mathrm{P}$ and $\mathrm{Ca}$ might be expected with a slope equal to the ratio of $\mathrm{Ca} / \mathrm{P}$ in bone salt $=2 \cdot 2 . \mathrm{P}$ is likely to be retained preferentially in soft tissue and therefore $\mathbf{P}$ retention should be positive at zero $\mathrm{Ca}$ retention and the linear correlation of $\mathrm{Ca}$ and $\mathrm{P}$ retention with slope $2 \cdot 2$ would disappear when $\mathrm{Ca}$ retention was negative. These expectations seem to be fulfilled by the observations (Fig. 3). Also included in Fig. 3 are the mean values for $\mathrm{Ca}$ and $\mathrm{P}$ retention in term breast-fed infants 6-8 days old with and without a dietary supplement of phosphate (Widdowson et al., 1963).

\section{Discussion}

The observations reported here seem to be internally consistent and understandable in simple terms 


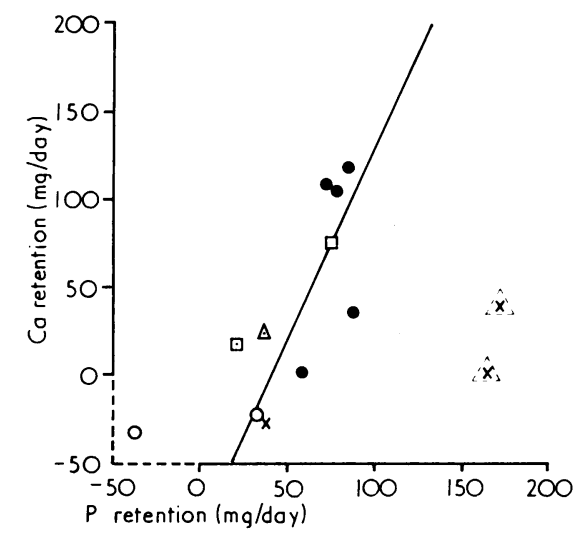

Fig. 3 Retention of $C a$ and $P$ in low birthweight infants on different cow's milk formulae. Milk $H$. milk $M \circ$, milk L singleton $\times$, twins Cases $3 a$ and $h \hat{\Delta} \dot{x}$. Mean values for breast-fed newborn normal infants (Widdowson et al., 1963) with phosphate supplement $\triangle$, without phosphate supplement $[\square$. The broken line is drawn with a slope $=2 \cdot 2$ (ratio $C a / P$ in bone salt) through the mean values for milk $H$ [].

if the intakes of $\mathrm{Ca}$ and of $\mathrm{P}$ are considered separately and not in terms of $\mathrm{Ca} / \mathrm{P}$ ratios. They suggest that true $\mathrm{Ca}$ absorption $A$ from the gut of low birthweight infants aged 4-41 days is proportional to intake and amounted to about $\frac{1}{3}$ of this for the particular formula used whether Ca intake was $\mathbf{4 0 0}$ or $200 \mathrm{mg}$ daily. There was little variation between different individuals in the fraction absorbed $A / I$, suggesting perhaps that absorption from cows' milk is a passive process in the human infant. True absorption and retention of $\mathrm{Ca}$ seemed to be independent of $\mathbf{P}$ intake. Thus on cows' milk formulae as well as with breast milk (Widdowson et al., 1963) a phosphate supplement did not affect significantly the retention of $\mathrm{Ca}$. A high level of $\mathrm{Ca}$ intake in cows' milk (milk H) may increase the deposition of bone salt in bone as compared with breast feeding (cf. Fig. 3).

Loss of $\mathrm{Ca}$ from the body into the bowel, the endogenous faecal $E$, was independent of both $\mathrm{Ca}$ and $\mathbf{P}$ intake and varied widely between different infants in the range $4-150 \mathrm{mg} /$ day. This individual variation in $E$ did not seem to depend on variations in body weight or in postnatal age over a limited range and the reasons for it are obscure. However such variation between individuals is potentially of great significance. Absorption of $\frac{1}{3}$ of a daily intake of $200-400 \mathrm{mg} \mathrm{Ca}$ amount to $67-133 \mathrm{mg}$ and whether an infant will have a positive or negative calcium balance $R$ will depend on the particular value of $E$ characteristic of that individual at that time (Fig. 2). It is remarkable that such large individual variations exist in $E$ but not in $A$ (cf. Fig. 1).

As noted earlier the equations used to calculate $E$ assumed that the transfer of $\mathrm{Ca}$ from blood to bowel lumen was irreversible, i.e. that the endogenous excretion was not accessible for reabsorption. This is clearly an unphysiological idea since endogenous excretion is likely to be the result of secretion of Cacontaining digestive juices (cf. Aubert et al., 1963). Further equations can be derived assuming that the fraction of digestive juice $\mathrm{Ca}$ absorbed is the same as that absorbed from food, but this is again an untestable assumption. As Marshall (1969) explained, digestive juice $\mathrm{Ca}$ cannot be measured by existing techniques and the quantity called endogenous faecal $\mathrm{Ca}$ is a parameter independent of a model of absorption or reabsorption from the digestive tract, i.e. independent of what proportion of digestive juice $\mathrm{Ca}$ may be absorbable.

If endogenous faecal excretion is thought of by analogy as intestinal clearance, an underlying assumption is that renal clearance and intestinal clearance, if they vary at all during a study period, vary together; that is, that if $f(t)$ describes the specific content of marker per $\mathrm{g} \mathrm{Ca}$ in plasma at time $t$ so that the urinary content of marker over the metabolic period from $O-T$ is $a \int_{O}^{T} f(t) d t$ and the corresponding faecal content of marker originating from intestinal clearance is $b \int_{O}^{T} f(t) d t$ then $a / b$ is constant throughout the period $O-T$. Variations in $a / b$ from time to time during an individual study period will contribute to the scatter of deduced values between different infants. However, if transfer of $\mathrm{Ca}$ from blood to bowel lumen is by means of secretion of digestive juices it will be an active process which may vary cyclically with time, depending on the needs for digestion, and $a / b$ might not be constant. Fortunately, perhaps, for our investigation the normal regular 4-hourly feeding of infants may cause $a / b$ to be more constant throughout a period $O-T$ of 48 hours' duration than would be the case for adults consuming three meals of varying size and content nonuniformly distributed through 24 hours of a day. Nevertheless, it is clear that there must be many difficulties in determing $E$ in milk-fed infants and we cannot claim that we have provided definitive values. $E$ can be determined directly by giving marker intravenously but we did not attempt this.

The mean plasma $\mathrm{Ca}$ concentration of newborn infants has been shown to depend to some extent on the composition of the feed (Barltrop and Oppé, 1970). The positive correlation of plasma $\mathrm{Ca}$ with 
the $\mathrm{Ca} / \mathrm{P}$ ratio of various milk formulae was statistically significant though the extent of the variation in mean plasma $\mathrm{Ca}$ was small, $9 \cdot 1-10 \cdot 2 \mathrm{mg} / 100 \mathrm{ml}$ compared with the range in $\mathrm{Ca} / \mathrm{P}$ from $0 \cdot 74-1 \cdot 8$, and the correlation depended entirely on the $9 \cdot 1 \mathrm{mg}$ value for high $\mathbf{P}$ milk, the other mean plasma values being statistically compatible with each other. It has been found that there is a wide range of individual values for plasma $\mathrm{Ca}$ and $\mathbf{P}$ for infants on a given formula (Barltrop and Oppé, 1970). It seems possible that this wide variability in plasma levels is correlated with the wide variability in endogenous faecal excretion reported here which seemed independent of $\mathrm{Ca} / \mathrm{P}$ ratios varying from 0.56 to $2 \cdot 4$. The difficulty in designing a single formula which will prevent the occurrence of neonatal hypocalcaemia could then be attributed to individual differences in a physiological characterstic of low birthweight (and perhaps all) infants.

Levels of $\mathbf{P}$ intake seem to play no special role: as far as the observations go, urinary levels seem to be passively determined by the differences between intake and retention. Retention of $P$ depended on the concomitant level of $\mathrm{Ca}$ retention, at least in part. It was inferred that absorption of $\mathbf{P}$ was largely complete at both levels of intake but proof that absorption is independent of intake will require observations analogous to those reported here on ${ }^{46} \mathrm{Ca}$. Since $\mathrm{Ca}$ and $\mathrm{P}$ seem to be treated differently by the bowel and do not seem to interact there in the low birthweight infant, thinking in terms of $\mathrm{Ca} / \mathrm{P}$ could be misleading.

The important new observation in this paper is the measurement of endogenous faecal excretion in the human infant, and the demonstration of its variability between individuals, and its probable independence of $\mathrm{Ca}$ and $\mathrm{P}$ levels in cows' milk formulae. The measurements were made possible by the application of a tracer method which avoids all irradiation of the subjects studied, and requires no more of the infant than accurate collection of urine and faeces and accurate determination of intake. The possibility is now open to examine other factors which may regulate the transport of calcium from the feed into the plasma, and from the plasma into the bowel of the infant.

The milk formulae were devised in collaboration with Dr. W. F. J. Cuthbertson (Glaxo Research Ltd.) and were prepared by Glaxo Laboratories Ltd., who also defrayed part of the costs. Miss $H$. Shepherd gave technical assistance, and Miss C. Copland, S.R.N., and Miss P. Dillon, S.R.N., undertook the metabolic balances. We thank Dr. J. Vennart for advice on preparation of the script.

\section{References}

Aubert, J.-P., Bronner, F., and Richelle, L. J. (1963). Quantitation of calcium metabolism. Theory. Journal of Clinical Investigation, 42, 885-897.

Barltrop, D., and Oppé, T. E. (1970). Dietary factors in neonatal calcium homoeostasis. Lancet, 2, 1333-1335.

Barltrop, D., and Oppé, T. E. (1973a). Absorption of fat and calcium by low birthweight infants from milks containing butterfat and olive oil. Archives of Disease in Childhood, 48, 496-501.

Barltrop, D., and Oppé, T. E. (1973b). Calcium and fat absorption by low birthweight infants from a calciumsupplemented milk formula. Archives of Disease in Childhood, 48, 580-582.

Barltrop, D., and Sutton, A. (1972). The use of ${ }^{46} \mathrm{Ca}$ to measure calcium absorption in the neonate. Nuclear Activation Techniques in the Life Sciences, p. 479. International Atomic Energy Agency. HMSO, London.

Fogg, D. N., and Wilkinson, N. T. (1958). The colorimetric determination of phosphorus. Analyst, 83, 406-414.

Marshall, J. H. (1969). Measurements and models of skeletal metabolism. Mineral Metabolism, Vol. 3, p. 2. Ed. by C. L. Comar and F. Bronner. Academic Press, New York.

Oppé. T. E., and Redstone, D. (1968). Calcium and phosphorus levels in healthy newborn infants given various types of milk. Lancet, 1, 1045-1048.

Shaw, J. C. L., Jones, A., and Gunther, M. (1973). Mineral content of brands of milk for infant feeding. British Medical Journal, 2, 12-17.

Southgate, D. A. T., Widdowson, E. M., Smits, B. J., Cooke, W. T., Walker, C. H. M., and Mathers, N. P. (1969). Absorption and excretion of calcium and fat by young infants. Lancet, 1, 487-489.

Sutton, A. and Barltrop, D. (1973). Absorption, accretion and endogenous faecal excretion of calcium by the newborn infant. Nature, 242, 265.

Sutton, A., Mole, R. H., and Barltrop, D. (1977). Urinary and faecal excretion of marker calcium $\left({ }^{46} \mathrm{Ca}\right)$ by low birthweight infants. Archives of Disease in Childhood, 52 , 50-55.

Widdowson, E. M., McCance, R. A., Harrison, G. E., and Sutton, A. (1963). Effect of giving phosphate supplements to breast-fed babies on absorption and excretion of calcium, strontium, magnesium, and phosphorus. Lancet, 2, 1250-1251.

Correspondence to Dr. D. Barltrop, Paediatric Unit, St. Mary's Hospital Medical School, London W2 1 PG. 